\title{
ASSESSMENT OF ENDOTRACHEAL TUBE INTUBATION. REVIEW OF EXISTING SCALES
}

\author{
Logan Glosser
}

Research Assistant, Cleveland Clinic Department of Anesthesiology Outcomes Research, Cleveland, United States

\begin{abstract}
Due to the complications associated with endotracheal intubation, contraindications should be assessed prior to initiating the procedure when possible. Several scales have been created to assess the ease of intubation. These intubation scales use numerous scoring systems combined with subjective assessments to provide a quantifiable suggestion for the patients difficulty of tracheal intubation. While there is no formal definition of what comprises a difficult intubation, some parameters include effort, number of attempts and complications. Some of the most common scales to assess this difficulty include the Mallampati score, the Cormack Lehane scale, the intubation difficulty scale, the level of difficulty of intubation, as well as the simplified airway risk index. There have been several other proposed methods as well that are less frequently used contributing to even less cohesion in the evaluation of airways.
\end{abstract}

KEY WORDS: endotracheal tube, intubation, grading scales

Disaster Emerg Med J 2017; 2(2): 91-93

\section{INTRODUCTION}

The endotracheal intubation procedure is integral to modern medicine and essential to emergency care, surgical practice and intensive care procedures. Prior to an operation, a patient is intubated under anaesthesia-induced sedation to maintain proper ventilation during the surgery. In emergencies, a patient may need to be intubated due to lack of consciousness, inadequate ventilation, acute respiratory failure or airway depression due to an altered mental status [1]. In either case, the establishment of the tube through the mouth into the trachea supports airflow from the mouth to the lungs. Correct placement of the tube often precludes the use of a laryngoscope, fiberoptic bronchoscope, or a video laryngoscope. Upon placement of the tube, a mechanical ventilator can be connected to provide artificial respiration when a patient cannot maintain adequate respiratory function.

The doctor or emergency medical technician performing the endotracheal intubation often inserts the tube using a laryngoscope to ensure that the tube is inserted through the glottis. Several problems can arise without the correct establishment of this artificial airway, however. If the tube is unintentionally placed in the oesophagus, posterior to the glottis, the airway will not be established. Without a functional airway, brain damage, cardiac arrest, and eventual death can occur. If the tube penetrates past the trachea into the bronchi, only one lung will be ventilated and can further result in a pneumothorax [2]. These complications can be exacerbated, particularly with difficult intubations [3]. In emergency scenarios or situations in which prolonged airway support is required, a cricothyrotomy or tracheotomy may be performed. Providing this information to practitioners performing intubation is clinically relevant as failure to intubate the trachea occurs one in 2,000 in the non-obstetric population and one in 300 in the obese [4].

Due to the complications associated with endotracheal intubation, contraindications should be assessed prior to initiating the procedure when possible. Several scales have been created to assess 
the ease of intubation. These intubation scales use numerous scoring systems combined with subjective assessments in order to provide a quantifiable suggestion for the patients difficulty of tracheal intubation. While there is no formal definition of what comprises a difficult intubation, some parameters include effort, number of attempts and complications. Some of the most common scales to assess this difficulty include the Mallampati score, the Cormack Lehane scale, the intubation difficulty scale, the level of difficulty of intubation, as well as the simplified airway risk index. There have also been several other proposed methods that are less frequently used, contributing to even less cohesion in the evaluation of airways.

\section{DISCUSSION}

The Mallampati score (Mallampati classification) is a test that comprises a visual assessment by an anaesthesiologist. While originally a 3 point scoring system, a modified Mallampati score consists of a 4 point scale to increase its range and accuracy (Fig. 1) [5]. The scoring is based on the distance from the base of the tongue to the roof of the mouth. Classes one and two are associated with a relative ease of intubation, while classes three and four indicate increasing difficulty as visualized below [4]. Research indicates that while this system may help in the prediction and assessment of difficult airways, it is much more effective when used in combination with other tests. Furthermore, this test alone is not sufficient to make an accurate decision [6].

One of the most commonly used methods to describe the laryngeal view during direct laryngoscopy is the Cormack-Lehane classification system [7]. Created in 1984, this grading system has widespread use in the assessment of patient airways. This system, similar to the modified Mallampati scale, has four grades. The Cormack-Lehane system has also been modified to split grade 2 into two parts, $a$ and $b$, in order to provide more accurate grading. The difference between the Cormack Lehane (CL) system and the Mallampati scale is that $\mathrm{CL}$ evaluates patients during laryngoscopy while the Mallampati scale is simply a visualization of the patient's throat [8]. Unfortunately, this scale also uses a high degree of subjectivity in its evaluation and there are numerous discrepancies in reported grade incidences [9].
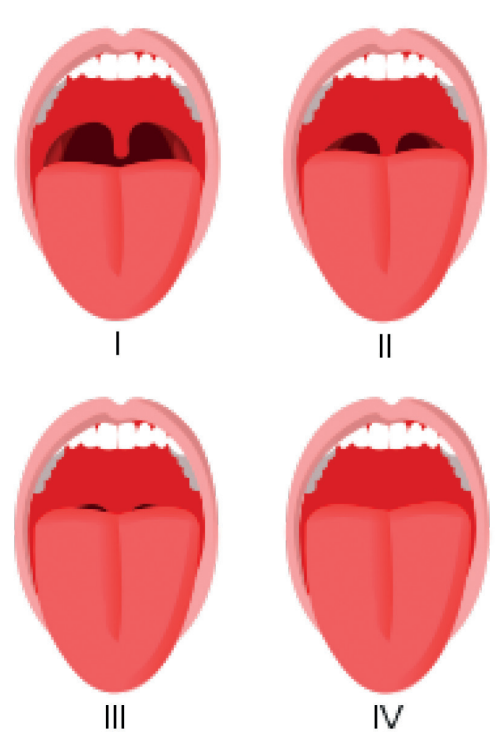

FIGURE 1. A diagram of the Mallampati classifications 1 through 4. Class one there is complete visualization of the soft palate, class two has only complete visualization of the uvula, class three only visualizes the base of the uvula, while in class four the soft palate is not visible

A slightly more objective scoring system has been proposed termed the Intubation Difficulty Scale score. This system uses seven parameters, 4 objective and 3 subjective scores. This system also integrates the Cormack-Lehane grade as one of the subjective assessments. This grading system evaluates the relative difficulty after intubation however, which differs from the Mallampati and Cormack-Lehane grading systems. While this could potentially provide practitioners information for future intubations, the intubation difficulty scale does not provide any information prior to intubation [10].

Another more complex system of evaluation proposed is the Simplified Airway Risk Index (SARI). SARI is a multivariate risk index with a numerical range from zero to twelve, with higher numbers indicating a more difficult airway. SARI uses seven parameters including the mouth opening, thyromental distance, the Mallampati score, movement of the neck, ability to create and underbite, body weight, as well as previous intubation history. This index combines the preoperative subjective assessments with some objective data and prior history [11].

Similar to the IDS, the Level of Difficulty of Intubation (LDI) scale has been proposed to evaluate the level of difficulty after intubation attempts. This system uses 4 levels based on the actions necessary during intubation (Tab. 1) [12]. 
Table 1. Level of Difficulty of Intubation (LDI) scale assessment according to 4 classifications criteria [12]

\begin{tabular}{|l|l|}
\hline LDI 1 & Straightforward. No modifications to usual technique required \\
\hline LDI 2 & After initial attempt, need to apply laryngeal or cricoid pressure, adjust patient position, or reintroduce blade \\
\hline LDI 3 & Change of blade, change of operator, or elective fiberoptic intubation \\
\hline LDI 4 & $\begin{array}{l}\text { Non-elective fibre optic intubation, emergent LMA, retrograde wire, cricothyroidotomy, tracheotomy, or failed } \\
\text { intubation }\end{array}$ \\
\hline
\end{tabular}

\section{CONCLUSION}

As illustrated in this article, there is no uniform method of description of what a difficult airway consists. Due to this and a lack of standardization for a definitive method for evaluating difficult intubation, the prevalence and factors associated with intubation difficulty have a wide variation. The American Society of Anesthesiologists currently recommends that a preoperative assessment of patient airways is performed based on eleven anatomical parameters [13]. Nonetheless, there is no clearly established recommendation on mandating examination, nor any clearly defined parameters for trading [14]. The UK does not recommend any preoperative airway assessment due to the confusion and lack of standardization of evaluating airways for intubation difficulty [15]. If a reliable scale for grading the level of difficulty of tracheal intubation could be established, it could improve patient safety and intubation outcomes.

\section{Conflict of interest: None declared.}

\section{REFERENCES}

1. Ezri T, Warters RD. Indications for tracheal intubation. In: Hagberg CA. ed. Benumof's Airway Management: Principles and Practice, 2nd ed. Mosby, Philadelphia 2007: 371.

2. Finucane BT, Santora AH. Principles of Airway Management. Springer Verlag, New York 2003.

3. Hagberg CA, Boin MH. Management of the airway: Complications. In: Saidman U, Benumof JL. ed. Anesthesia and Perioperative Complications, 2nd ed. Mosby, St. Louis 1999: 3.

4. Samsoon GL, Young JR. Difficult tracheal intubation: a retrospective study. Anaesthesia. 1987; 42(5): 487-490, indexed in Pubmed: 3592174.

5. Mallampati SR, Gatt SP, Gugino LD, et al. A clinical sign to predict difficult tracheal intubation: a prospective study. Can Anaesth Soc J. 1985; 32(4): 429-434, indexed in Pubmed: 4027773.
6. Lee A, Fan LTY, Gin T, et al. A systematic review (meta-analysis) of the accuracy of the Mallampati tests to predict the difficult airway. Anesth Analg. 2006; 102(6): 1867-1878, doi: 10.1213/01. ane.0000217211.12232.55, indexed in Pubmed: 16717341.

7. Gal TJ. Airway management. In: Miller DM, Fleisher LA, Johns RA, Savarese JJ, Winer-Kronish JP, Young WL. ed. Miller's Anesthesia. Elsevier, Philadelphia 2005: 1617-1652.

8. Cormack RS, Lehane J. Difficult tracheal intubation in obstetrics. Anaesthesia. 1984; 39(11): 1105-1111, indexed in Pubmed: 6507827.

9. Cormack RS. Cormack-Lehane classification revisited. British Journal of Anaesthesia. 2010; 105(6): 867-868, doi: 10.1093/bja/aeq324.

10. Adnet $F$, Borron SW, Racine SX, et al. The intubation difficulty scale (IDS): proposal and evaluation of a new score characterizing the complexity of endotracheal intubation. Anesthesiology. 1997; 87(6): 1290-1297, indexed in Pubmed: 9416711.

11. Nørskov AK, Rosenstock CV, Wetterslev J, et al. Incidence of unanticipated difficult airway using an objective airway score versus a standard clinical airway assessment: the DIFFICAIR trial - trial protocol for a cluster randomized clinical trial. Trials. 2013; 14: 347, doi: 10.1186/1745-6215-14-347, indexed in Pubmed: 24152537.

12. Prasad RV, Dogra S, Johnson B. Classifying The Difficulty Of Intubations. Anesthesia \& Analgesia. 1998; 86(Suppl), doi: 10.1097/00000539199802001-00174.

13. Caplan R, Benumof J, Berry F. Practice guidelines for management of the difficult airway: an updated report by the American society of anesthesiologists task force on management of the difficult airway. Anesthesiology. 2003; 98(5): 1269-1277, doi: 10.1097/00000542200305000-00032.

14. Apfelbaum JL, Hagberg CA, Caplan RA, et al. American Society of Anesthesiologists Task Force on Management of the Difficult Airway. Practice guidelines for management of the difficult airway: an updated report by the American Society of Anesthesiologists Task Force on Management of the Difficult Airway. Anesthesiology. 2013; 118(2): 251-270, doi: 10.1097/ALN.0b013e31827773b2, indexed in Pubmed: 23364566.

15. Henderson JJ, Popat MT, Latto IP, et al. Difficult Airway Society. Difficult Airway Society guidelines for management of the unanticipated difficult intubation. Anaesthesia. 2004; 59(7): 675-694, doi: 10.1111/j.1365-2044.2004.03831.x, indexed in Pubmed: 15200543. 